\title{
GESTÃO DA POLÍTICA DE SAÚDE E AS ORGANIZAÇÕES DO TERCEIRO SETOR $^{1}$
}

\author{
Luciano A Prates Junqueira ${ }^{2}$
}

\section{RESUMO}

A descentralização que vem ocorrendo no aparato estatal brasileiro transfere para o terceiro setor, também denominado organizações sem fins lucrativos, competências para a gestão das políticas sociais de responsabilidade do Estado. Essas organizações em caráter complementar realizam, em parceria com o Estado, a prestação de serviços de saúde, constituindo uma alternativa para fazer frente aos problemas que afetam a população. As instituições sem fins lucrativos e as organizações estatais, articulando-as em ações de atenção, facilitam o acesso da clientela ao atendimento, dando maior resolutividade aos problemas de saúde sem contudo substituir a ação do Estado, que dispõe de maior capacidade de cobertura das demandas de saúde.

Palavras chaves: gestão; política de saúde; terceiro setor; descentralização; parceria; ação estatal

\section{SUMMARY}

The decentralization that comes occurring in the Brazilian state apparatus transfers to the third sector, also called non-profit organizations, abilities for the management of the social politics of responsibility of the State. These organizations in complementary character carry through, in partnership with the State, the rendering of services of health, constituting an alternative to make front to the problems that affect the population. The non-profit institutions and the state organizations, articulating them in action of attention, facilitate to the access of the clientele to the attendance, giving bigger resolubility to the problems of health without however substituting the action of the State, that makes use of bigger capacity of covering of the health demands.

Key words: management; health politics; third sector; descentralization; partnership; state action.

\footnotetext{
${ }^{1}$ Uma versão deste artigo foi apresntada no XI Congresso Brasileiro de Sociologia, realizado na UNICAMP Campinas,SP de 1 a 5/09/2003.

${ }^{2}$ Sociólogo, Doutor em Administração da Saúde, Professor Titular da Faculdade de Economia, Administração, Contabilidade e Atuária - FEA/PUCSP, Coordenador do Programa de Estudos PósGraduados em Administração da PUCSP e do Núcleo de Estudos Avançados do Terceiro Setor NEATS/PUCSP e Professor Assistente Doutor do Programa de Gestão de Negócios da UNISANTOS e-mail junq@pucsp.br
} 


\section{INTRODUÇÃO}

A ação social busca hoje um novo referencial, compartilhado por setores governamentais e não governamentais, para combater a pobreza e a exclusão social. Busca-se sair de uma lógica assistencialista, que permeava os programas sociais, para fortalecer a capacidade de pessoas e comunidades de satisfazer suas necessidades e construírem uma vida com qualidade.

Novas iniciativas tanto do governo como da sociedade promovem a participação dos cidadãos e incentivam formas inovadoras de mobilização e parcerias, para construir uma sociedade solidária através de processos de desenvolvimento social sustentável. Com isso estabelece-se um novo padrão de relação entre Estado e Sociedade.

Neste contexto é que queremos colocar a questão da gestão da política de saúde, que ainda é apenas competência do Estado. Com o surgimento do terceiro setor, um novo ator é introduzido nesse processo e a discussão assume outro contorno.

Vamos começar nossa discussão pela política de saúde como dever do Estado visualizando aí a relação Estado e Sociedade, as contradições entre o dever do Estado de suprir necessidades do cidadão e a responsabilidade da sociedade.

Em seguida, discutiremos as mudanças que vêm ocorrendo no aparato estatal, por ocasião do esgotamento do Estado do Bem Estar Social, situando a descentralização como um processo e as diversas formas que vem assumindo para a gestão das políticas sociais, e , em particular, a de saúde.

Depois discutiremos o papel que a sociedade pode passar a desempenhar na gestão da política de saúde e a parceria com o denominado terceiro setor, as transformações que podem ocasionar essa relação para melhoria da qualidade de vida da população. 


\section{POLÍTICA DE SAÚdE: DEVER DO ESTADO E DIREITO DOS} CIDADÃOS?

O desenho da sociedade mudou. Não existe apenas a relação Estado e Mercado.

A visão de que grupos de cidadãos se mobilizam apenas para cobrar ações do Estado foi modificada, porque eles tomam iniciativas próprias para resolver seus problemas.

A cidadania não se limita ao voto, mas, também, à participação na administração da cidade, para melhorar a escola, o hospital, até, enfim, realizar trabalhos em prol do bem comum, seja de iniciativa do governo ou de uma organização da própria sociedade. As iniciativas privadas com fins públicos se multiplicam. Essas iniciativas estão redefinindo os padrões da relação Estado e Sociedade.

As parcerias envolvendo diversos atores não constituem alternativa ao Estado na gestão das políticas sociais, mas a sociedade assumindo parte da sua responsabilidade social. Este é um fenômeno recente, onde a sociedade, com seus diversos atores, é desafiada a produzir juízos de valor e formular escolhas sem apenas conformar-se ao pré-estabelecido, reinventando e reconstruindo-se para fazer frente a novos desafios (GIDDENS E CASTELLS) e deliberando coletivamente.

Esse é um processo que está ainda em construção, exigindo mudanças, tanto por parte do Estado como da sociedade civil, de suas organizações, pois há preconceitos, desconfianças de ambas as partes. Isso exige interações, respeito aos papéis e identidades. Quanto mais parcerias se estabeleçam, mais recursos serão mobilizados, maior será o impacto redistributivo dos programas públicos e menores os riscos de desperdícios, clientelismo e mesmo corrupção.

Essa nova relação entre Estado e Sociedade configura uma nova dinâmica, mas não altera papéis. Redefine o compartilhamento de responsabilidades. 
Com isso a lógica das políticas sociais e, em especial da saúde, deixa de ser perpassada apenas pelo dever do Estado de oferecer melhores condições de vida para a população, através do atendimento de necessidades, mas de direitos. Com essa nova lógica os direitos dos cidadãos não são apenas de responsabilidade do Estado, mas também da própria sociedade.

Essa discussão no Brasil não é recente. Ela vem no bojo da transformação do Estado e de suas competências. Por isso é que se diz que não há contradição entre políticas públicas e sociedade, entre oferta de serviço e fortalecimento do capital local.

A política de saúde é parte do processo estatal de alocação e distribuição de valores, é o estado intervindo na realidade social para promover direitos sociais e garantir aos cidadãos seus direitos.

Essa discussão remete para a relação estado $x$ sociedade, para as transformações que vêem ocorrendo com o Estado, a partir da década de 70 com a crise do Estado do Bem Estar Social. O processo de transformação do Estado que ocorre a partir do inicio dessa crise, que tem na descentralização um de seus pressupostos que passaremos a discutir.

\section{A DESCENTRALIZAÇÃO E AS TRANSFORMAÇÕES DO APARATO ESTATAL EM SAÚDE}

Em um país como o Brasil, com grande diversidade regional e com uma forte tradição centralizadora do Estado no que diz respeito à formulação e implementação de suas políticas, chama a atenção 0 movimento de descentralização que tem ocorrido no setor saúde.

Esse movimento político administrativo do setor, vem no bojo do processo da reforma do Estado que vem ocorrendo desde a década de 70 e ganha maior definição nos anos 80. Essas reformas têm como objetivo dar maior governabilidade e governança ao Estado, ou seja, "garantir condições democráticas de governá-lo, torná-lo mais eficiente de forma a atender as 
demandas dos cidadãos com melhor qualidade e a custo menor"( BRESSER PEREIRA, 1998:32).

A crise dos anos 80 foi marcada pelo colapso do Estado Social quando emerge o conceito de descentralização como estratégia de mudança para o poder centralizado. Isso ocorreu, inicialmente, nos países centrais democráticos, como alternativa à crise do Estado do Bem-Estar Social, que como Estado protetor teve uma enorme expansão do seu aparato burocrático. Essa expansão se deu em função da gestão das políticas sociais, o que ocasionou uma acentuada centralização das decisões, comprometendo sua eficácia.

Apesar das diferenças conceituais no âmbito da gestão pública, a descentralização tem um significado precípuo o da transferência de poder dos níveis centrais de governo para os mais periféricos, gerando autonomia de gestão em oposição a um poder centralizado e burocratizado. Assim, a descentralização emerge em oposição ao poder centralizado, determinando formas diversas de organização através da criação de instâncias de poder, tornando-o permeável aos interesses da sociedade para dar maior eficácia à gestão.

A descentralização surge assim, como uma alternativa de mudança, como um instrumento para racionalizar e dar eficácia ao aparato estatal das políticas sociais. Constituindo uma das estratégias para a reestruturação desse aparato

O Estado do Bem Estar Social constituído depois da II Guerra como uma forma de regulação social, no âmbito de um determinado estágio de desenvolvimento do capitalismo, expressa-se nas relações entre Estado e Economia, e Estado e Sociedade, manifestando-se na organização e produção de bens e serviços coletivos públicos ou privados, regulados pelo Estado (DRAIBE, 1989:29). Esse Estado, nos paises desenvolvidos, nos meados dos anos 70, chega ao esgotamento, no entanto, é importante saber se o capitalismo desenvolvido pode prescindir desse Estado social.

Nessa leitura, a descentralização surge como exigência de redução do tamanho do Estado, para que ganhe em agilidade e em eficiência, mas sem excluir do seu âmbito o sistema de políticas sociais. 
Nesse contexto que deve ser entendido o movimento de descentralização político administrativa do setor saúde no Brasil. Desenvolveu-se a partir dos anos 80 e teve consequências importantes para distribuição de competências entre os três níveis de governo na instituição do Sistema Único de Saúde. - SUS.

O Sistema Único de Saúde definiu, para o Brasil, um novo modelo de atenção à saúde. Constitucionalmente, para cada nível de governo, foram atribuídas novas competências e nesse processo tanto estados como municípios passaram a ter responsabilidades específicas na gestão do SUS.

Essa novidade tem mais de uma década. Contudo, ainda há uma distância entre o formal e o real. A vontade de mudar expressa em uma lei não é suficiente para transformar as práticas institucionais e sociais das organizações envolvidas no processo.

O novo modelo de atenção à saúde exigia que se estabelecesse um processo de transferência de poder e de recursos do nível federal para os níveis estadual e municipal. No entanto, num país do tamanho e da complexidade do Brasil, esse processo exigiu e ainda exige mudanças de várias ordens, pois não é apenas através de instrumentos e medidas legais que isso se viabiliza.

Além disso, a mudança que se pretende alcançar com o SUS implica não apenas a transferência de recursos e atribuições, mas também a alteração de formatos institucionais e, sobretudo, de práticas de gestão. E isso deve ocorrer tanto nas organizações que transferem como naquelas que recebem as atribuições.

Esse projeto que tem a descentralização como uma das suas diretrizes determina um novo formato para o aparato estatal da saúde, constituindo um instrumento de mudança, tornando-o mais permeável aos interesses coletivos..

A descentralização definida, então, como uma das diretrizes do SUS se deu de maneira bastante acentuada na primeira década de desenvolvimento desse sistema, o que ocasionou uma redistribuição das responsabilidades gestoras entre os três níveis de governo - federal, estadual e municipal.

Essa redistribuição de responsabilidades gestoras, expressa em toda a legislação complementar do SUS, particularmente instrumentalizada com as 
edições das Normas Operacionais Básicas 1/93, 1/96 e Norma Operacional de Atenção a Saúde - NOAS 2001, acabaram induzindo, com grande ênfase, o processo de municipalização da saúde sem, contudo, dar conta de outras mudanças também necessárias, quando se considera as novas atribuições de cada nível de governo.

O processo de descentralização, no entanto, não garante, por si só que todos os municípios realizem uma gestão eficaz, pois nem todos possuem as mesmas condições para atenderem as necessidades de saúde da população, nem ao nível estadual assumir seu papel de regulação.

Esse nível de governo, transferindo para os municípios a sua rede ambulatorial e parte da hospitalar, foi saindo do papel de prestador, mas não se capacitou para assumir suas novas atribuições de gestor do SUS. O processo de descentralização instaurado pelo SUS, centrado na relação governo federal e municípios, como prestadores, deixou à margem os estados, como instâncias de planejamento, financiamento, avaliação e controle. Com isso o nível estadual de governo permaneceu na disputa pelo papel de prestador e o SUS deixou de dispor de uma instância que articulasse e otimizasse os recursos assistências existentes em cada município, obedecendo uma programação e a operação da rede de serviços de âmbito regional.

Sem essa instância de integração e de desenvolvimento regional, típica do modelo de Estado federativo, os municípios, considerados isoladamente, reforçam seu papel mas também as desigualdades entre si. Aqueles dotados de maior recursos institucionais tendem a melhorar o acesso e a qualidade dos serviços prestados à sua população. Aqueles sem infra-estrutura de serviços e capacidade gerencial permanecem incapazes de dar respostas às necessidades da sua população, que inclusive passa a pressionar os municípios dotados de mais recursos, gerando um círculo vicioso, que acentua as distorções regionais.

O processo de transferência da gestão da rede para os municípios tem sido longo, em função, inclusive, das desigualdades dos municípios. Isso tem determinado uma dubiedade na redefinição do papel das secretarias estaduais de 
saúde, pois permanecendo como prestadoras dificilmente conseguem exercer suas tarefas de regulação.

A requalificação do papel do Estado, a reestruturação organizacional e a reorientação do processo de trabalho das instâncias gestoras em cada nível de governo, são medidas imprescindíveis ao processo de consolidação do SUS ${ }^{3}$.

O processo de descentralização acarretou uma polarização entre o governo federal, com poder financeiro e normatizador, e os municípios, permanecendo o gestor estadual do sistema com uma posição tímida, permitindo, inclusive, afirmar que as Secretarias de Estado da Saúde vivem, hoje, uma crise de identidade institucional.

Assim, o fortalecimento do papel do Estado na gestão do SUS demanda uma revisão das competências dos três níveis de governo, mas considerando as mudanças que vêm ocorrendo nas relações Estado, Sociedade e Mercado. Nesse sentido, não se pode dizer do fortalecimento da gestão do Estado, do seu papel regulador na saúde, sem considerar as características e a natureza que assume o setor privado.

A complexidade da sociedade, o desenvolvimento tecnológico faz com que também na saúde, na perspectiva de um sistema único, se deixe de privilegiar a lógica hierárquica, o poder centralizador, para valorizar a organização em rede. Isso determina a busca de soluções renovadas, evitando a solução padronizada que enquadra situações diferentes em um mesmo formato institucional. Nessa lógica não é o Estado, com sua burocracia e nem o mercado, na busca de lucros, que vão assegurar o funcionamento adequado das organizações, mas uma nova relação que se estabelece entre esses atores e a sociedade civil.

\section{O TERCEIRO SETOR E A GESTÃO DA POLÍTICA DE SAÚDE}

A eficácia da gestão da política de saúde não depende apenas da vontade política de quem tem o poder e mesmo dos recursos disponíveis, da transferência de poder independente de quem o recebe. Mas de um projeto articulado com 
outras políticas sociais, incorporando atores individuais e institucionais públicos e privados, para mudar a lógica da gestão.

Nesse contexto é que as instituições sem fins lucrativos, que no dizer de Drucker (1994:40) não fornecem bens ou serviços, mas o ser humano mudado, constituem aquilo que o autor denomina de uma segunda contra-cultura a "das instituições não lucrativas e não-governamentais do "terceiro setor", pois seus voluntários não-remunerados constituem" uma força de trabalho que "possuem um espirito distinto, valores distintos e prestam uma contribuição distinta à sociedade" (DRUCKER, 1997:159). São organizações que envolvem pessoas comprometidas com o bem coletivo, onde a iniciativa individual não privilegia interesses individuais, mas o coletivo.

Essas organizações sem fins lucrativos, não-governamentais constituem aquilo que se denomina terceiro setor, nem Estado nem mercado. São organizações públicas privadas, porque não estão voltadas à distribuição de lucros para acionistas ou diretores, mas para a realização de interesses públicos, entretanto, desvinculadas do aparato estatal.

Essa nova realidade que está sendo construída estabelece uma nova relação entre Estado e Sociedade, entre público e privado. Se até período recente o Estado era o promotor exclusivo das políticas sociais, esta realidade começou a mudar em função das demandas e pressões advindas das pessoas e grupos organizados, até mesmo dos organismos governamentais que buscam novas formas de gestão, novas maneiras de atender as necessidades sociais.

Essa abordagem é fundamental. Do contrário estaremos sempre na dependência dos recursos orçamentários, da sensibilidade dos políticos no poder às demandas dos desprotegidos, às suas carências. Mudar essa formulação é uma tarefa que exige que as políticas sociais passem de um estatuto de carência para um de direitos (OLIVEIRA, 1994:4). Com isso iniciase um processo de mudança da lógica que ainda informa as organizações filantrópicas, atender os excluídos.

\footnotetext{
${ }^{3}$ A NOB-01/93 e a NOB-01/96 dos 5506 municípios brasileiros, em 2001, 99,0\% estava habilitado na gestão plena da atenção básica e $10,0 \%$ na gestão plena do sistema municipal.
} 
É um processo que exige a atualização das propostas mediante o envolvimento dos diversos segmentos sociais no âmbito das organizações e da própria sociedade. Isso significa a construção de uma nova realidade social onde o que se denominava de carentes, de excluídos, deixam de ser objeto de benemerência do Estado e das classes mais abastadas, para tornarem-se sujeitos de direitos. Isso significa mudar a cena política, pois todos cidadãos passam a ter direitos de acesso à saúde, à educação, à habitação e a outras condições sociais que Ihes garantam uma vida com qualidade.

Nessa perspectiva, as políticas sociais passam a ser formuladas como direitos dos cidadãos e dever do Estado conforme define a Constituição de 1988. O objetivo é chegar a uma distribuição mais equitativa da riqueza, onde os mais pobres, como sujeitos buscam valer seus direitos de cidadãos. Isso traz implícito a construção da cidadania, que deve resultar em novas relações entre Estado e Sociedade.

Essa construção exige mudanças significativas no Estado, no seu aparato burocrático e na própria Sociedade. Coloca-se a necessidade da reforma do Estado e das suas organizações. Nesse contexto predominam críticas "às organizações burocráticas, em que se alternam preocupações políticas sobre o caráter antidemocrático dessas organizações com preocupações ligadas à eficiência administrativa e ao custo dos serviços prestados pelo Estado" (RIBEIRO, 1997:19).

No cenário de modernização econômica do Estado que, no Brasil, a reforma ganha força e as organizações sem fins lucrativos ganham espaço na cena política. Passam a constituir uma alternativa de eficácia à gestão das políticas sociais. O Estado sem eximir de sua responsabilidade transfere algumas de suas competências para organizações da sociedade civil, que passam a assumir, em caráter complementar e, em parceria, ações sociais que possibilitam oferecer à população melhores condições de vida.

O ajuste que se pretende entre Estado e Sociedade não é a desmontagem do aparato estatal para reduzir gastos, mas para ordená-lo de acordo com uma nova lógica, que não é a do mercado mas a das demandas 
sociais, da preservação dos direitos sociais já conquistados. Ademais uma sociedade de classes não vive sem o Estado. Aquilo que é específico do Estado não poderá ser redistribuído.

A transformação que se estabelece com a transferência das competências para organizações que estão fora do Estado e do mercado, favorecendo o surgimento daquilo que se denomina de terceiro setor. Mas como esse novo setor não é capaz de regulamentar-se, segundo Fernandes ( 1997:31) de acordo com normas de aceitação universal a presença do Estado se faz necessária para regular as relações. "E o sistema legal, instituído e mantido pelo estado, que esclarece os limites das ações voluntárias consideradas legítimas".

Nesse sentido, essas organizações vivem também um processo de institucionalização, que depende tanto de sua finalidade como das relações que estabelecem tanto com o Estado como com os agentes econômicos. Nessa perspectiva, é que se deve entender a Lei 9 790, de 23.03.1999. Com essa Lei o Estado dispõe sobre a qualificação de pessoas jurídicas de direito privado sem fins lucrativos, como Organizações da Sociedade Civil de Interesse Público, definindo os termos em que deve ocorrer a parceria dessas instituições com o Estado, na realização de ações sociais de sua competência.

Como são organizações constituídas para o atendimento dos interesses públicos, a parceria que estabelecem com o Estado tem um caráter complementar, enquanto colabora com o estado naquilo que lhe é específico. Essas organizações da sociedade civil assumem um papel ativo na construção da cidadania. A crença é de que a ação desses entes privados torna mais eficaz o atendimento das demandas sociais da população.

Segundo Tenório (1999:89) essas organizações do terceiro setor são "agentes não-econômicos e não-estatais que procuram atuar, coletiva e formalmente, para o bem-estar de uma comunidade ou sociedade local, subregional ou regional, nacional ou internacional. A ação coletiva dessas organizações pressupõe a sua democratização para permitir a emancipação 
dos sujeitos sociais mediante o exercício da cidadania". Nesse sentido, elas estão presentes hoje tanto nas sociedades ricas como nas pobres, para atender ou capitalizar anseios da sociedade ou de seus segmentos. Desempenham em alguns casos um papel importante para a conquista da justiça social em situações em que os agentes econômicos e nem mesmo o Estado mobilizam-se para atender. No entanto essa instituições dependem também desses setores para, em parceria, atender as demandas sociais.

Daí o grande desafio de ver, "como a partir do social, o mercado pode ser reinventado, para satisfazer as necessidades de bens e serviços da maioria da população .. e como se pode reinventar o Estado enquanto extensão de um contrato social que reflita essa relação, onde as pessoas estejam no centro das preocupações políticas" (THOMPSON, 1997:47)

Como instituições de base comunitária essas organizações sem fins lucrativos congregam pessoas, geralmente, de um mesma base territorial que buscam resolver os problemas sociais que os afetam. Nessa perspectiva, é que Dowbor (1998:426) diz que se trata "de formas da sociedade civil assumir diretamente a resolução de alguns de seus problemas" sem esperar a intervenção do Estado ou dos agentes econômicos. O objetivo é garantir aos cidadãos seus direitos sociais, seja em parceria com o Estado ou com os agentes econômicos que de tenham compromisso com a sociedade.

A articulação dessas instituições e pessoas, constituindo redes sociais, em torno de uma idéia força que possibilita o enfrentamento dos problemas sociais. Essa interrelação de pessoas e organizações permite um olhar diferente dos problemas sociais que apresentam características e complexidade crescentes. A complexidade desses problemas não pode ser encarada apenas da ótica de uma política, mas da integração de diversas políticas sociais, numa perspectiva intersetorial. Isso permitirá compreender e identificar soluções que possibilitem à população uma vida com qualidade.

Portanto, não é nem a estatização e nem a privatização, mas a construção de relações entre Estado, empresas e sociedade, de um lado, e de outro entre os 
três níveis de governo que determina uma nova dinâmica no fortalecimento da gestão do SUS. Nessa perspectiva que se coloca a gestão dos serviços de saúde e mesmo da política de saúde.

Não basta privatizar ou estatizar um hospital, ou outro serviço de saúde, tanto faz privatizar como entregá-lo à gestão privada pública, de nada adianta se não houver um controle pelo conselho de cidadãos e a regulamentação do governo do Estado. Mesmo com outras alternativas de articulação, se houver, o importante é a presença da sociedade civil.

Essas articulações podem nos parecer estranhas, porque distantes de nossa realidade e não cabem nas nossas simplificações ideológicas, mas sem dúvida temos de evoluir nessa direção para estabelecer diversos mecanismos de regulação, especialmente no setor saúde. Onde o estado, perdendo seu papel de interventor ou prestador, tem buscado novos meios para tornar-se mais eficiente e melhor capacitado para defender o patrimônio público e atender as demandas dos cidadãos, garantindo seus direitos sociais e uma vida com qualidade.

A descentralização como transferência de poder para junto do usuário, também significa dotar a sociedade civil de um novo papel. E essa nova realidade social pede soluções diversificadas e socialmente mais justas que devem ocorrer na cidade.

Esse processo de transformação de um Estado centralizado e todo poderoso, para um Estado com competências distribuídas pelos três níveis de governo, demanda um plano de articulação das diversas forças sociais. Isso não significa privilegiar o Estado, o mercado e a sociedade civil organizada, mas a articulação entre esses segmentos. Essa é uma nova realidade social no Brasil, fazer com que a sociedade civil passe a ocupar um papel na cena política, pois tanto o Estado como as empresas não respondem de maneira adequada às necessidades de qualidade de vida da população.

Assim, fortalecer o Estado na gestão e regulação do SUS, estabelecendo relações com o setor privado, mediadas pela sociedade civil organizada, é um processo ainda incipiente no país. E isso é novo, porque, em geral, na saúde, numa perspectiva corporativa, não se tem o cuidado de distinguir organizações 
sem fins lucrativos daquelas que estão voltadas para o lucro. É um reducionismo que desconhece o papel que essas organizações sem fins lucrativos podem ter, em caracter complementar, na gestão das política de saúde.

A discussão recorrente no Brasil é da relação entre os três poderes executivo, legislativo e judiciário, estando a sociedade civil presente apenas pelo voto e o setor privado como lobista e contribuindo nas campanhas eleitorais. Essa colocação pode resgatar ( DOWBOR 2000:9), a capacidade do Estado de organizar o novo pacto social. Reconhecer o poder político da sociedade civil organizada, pode significar sua mobilização para exercer o real papel de controle sobre o Estado, fazendo valer seus direitos inclusive para conter os abusos do setor privado.

Esse processo determina novas relações entre Estado, Sociedade e Mercado e cria uma nova dinâmica de regulação, atribuindo também ao Estado um novo papel para a construção de uma sociedade mais justa e equâmine que é a proposta do SUS. Nesse sentido a descentralização por se só não garante uma vida com qualidade e nem a prestação de serviços de saúde com qualidade. É necessário a organização de um sistema de controle que articule os três atores para fazer uma regulação que atenda as necessidades dos cidadãos., mediante a construção de uma sociedade solidária.

Nessa perspectiva também ganha sentido a intersetorialidade como uma das possibilidades de integrar a saúde com as outras políticas sociais A ação intersetorial não se esgota no âmbito de uma organização ou de uma política social, mas de várias organizações públicas, sejam privadas ou estatais, apontando para a necessidade de procurar outras saídas, para lidar com as incertezas e a complexidade dos problemas sociais. Os problemas sociais emergem da interação do sujeito com o mundo e sua percepção não é única, depende dos valores de cada ator social envolvido, e, como tal, sua solução também não será única, inclusive, porque as certezas absolutas perderam consistência.

Nesse contexto que se coloca também a noção de rede como um emaranhado de relações das quais os indivíduos constituem os nós, significa uma 
transformação das idéias sobre organização social. Mas ainda hoje temos dificuldades para incorporar as implicações da metáfora de rede tanto no nível das organizações como da sociedade (PAKMAN, 1995:301). As pessoas organizam seu significado em torno do que são e acreditam que são e as redes de intercâmbios conectam indivíduos, grupos, regiões e organizações de acordo com os objetivos processados na rede (CASTELLS, 199:23).

Nas redes os objetivos definidos coletivamente, articulam pessoas e instituições que se comprometem em superar de maneira integrada os problemas sociais. Essas redes são construídas entre seres sociais autônomos, que compartilham objetivos que orientam sua ação, respeitando a autonomia e as diferenças de cada membro. Daí a importância de que cada organização pública, seja estatal ou privada, desenvolva seu saber para colocá-lo de maneira integrada a serviço do interesse coletivo.

Sua verdade está na sua concretização, na superação das determinações sociais mediante o estabelecimento de parcerias entre sujeitos individuais ou coletivos, mobilizados por objetivos construídos e apropriados coletivamente, para a construção de uma nova realidade social (JUNQUEIRA, 1999: 64).

As organizações sem fins lucrativos, como integrantes dessas redes sociais, passam a constituir uma forma privilegiada de gestão das políticas sociais. No entanto, essas redes sociais também incorporam pessoas que voluntariamente a integram ajudando a tecê-la, colocando o seu saber, o seu tempo e experiência a serviço do bem público. Assim, o trabalho voluntário e sua organização constitui parte dessa rede como um meio de garantir aos diversos segmentos sociais uma vida com qualidade.

Essas organizações sem fins lucrativos na saúde podem assumir um papel importante na gestão da prestação dos serviços de saúde, sua contribuição pode ser um meio de mudar a oferta dos serviços de saúde. Com isso pode-se mudar a lógica da gestão das organizações estatais de saúde para dar eficácia aos serviços de saúde. Contudo, isso não significa substituir a prestação pública de saúde, mas definir parcerias com outras instituições de caráter público, mas 
privado, que poderão cooperar na gestão e na qualidade da prestação dos serviços públicos de saúde.

\section{CONCLUSÃO}

As mudanças que ocorreram e ainda vem ocorrendo no interior do aparato estatal brasileiro tem na descentralização uma das suas principais diretrizes. Transferências para as instâncias mais periféricas do poder e para entes públicos privados a gestão da política de saúde e das outras políticas sociais com o objetivo de garantir à população seus direitos sociais. Esse processo assumiu características singulares na política de saúde, a partir, principalmente, da década de 80.

Concomitante a esse processo também ganha relevância as organizações sem fins lucrativos, entes privados e autônomos voltados para o interesse coletivo que assumem um papel central na reconstrução da sociedade civil.

Como o aparato burocrático brasileiro é tido como ineficaz na gestão das políticas sociais, buscou-se, com a descentralização, encontrar outras saídas que garantissem aos cidadãos ter seus direitos respeitados. Nessa perspectiva, as organizações sociais sem substituir o Estado, mas em parceria com ele, como organismos da sociedade civil, recebem de volta competências que as integram no processo de reconstrução da Sociedade.

A proposta dessa parceria é de tornar mais ágil a gestão das políticas sociais, pois até então era apenas o Estado que realizava essa tarefa. Mas com seu aparato burocratizado e centralizado, com uma prática ineficiente e marcada pelo atendimento dos interesses de classes alojadas no seu interior procurou-se através da descentralização encontrar parceiros privados voltados para os interesses coletivos que atendessem as demandas sociais.

Essa realidade que se instaura na gestão das políticas sociais ganhou força na saúde, principalmente na gestão dos hospitais públicos, mas isso ainda 
é uma inovação recente no setor. Esse processo é feito com avaliação e controle por parte do Estado, pois enquanto transfere suas competências e disponibiliza recursos deve estabelecer um processo de regulação das instituições parceiras. Há várias experiências sendo realizadas no Estado de São Paulo, mas ainda não avaliadas e comparadas com que ocorre nas instituições estatais.

O Estado possui diversos órgãos especializados na gestão da políticas de saúde, mas apenas nos hospitais foi capaz de estabelecer parcerias ou mesmo transferir para essas instituições a gestão de seus próprios. Isso não quer dizer que não venha ocorrendo essa transferência, talvez o que está faltando são mecanismos de avaliação dessas transferências para verificar se essa gestão pública privada tem sido mais resolutiva e capaz de oferecer serviços de melhor qualidade.

A parceria das organizações sem fins lucrativos na gestão da política de saúde pode inovar e mudar a lógica da gestão pública, enquanto introduz novas formas de gerenciar a prestação de serviços de saúde. Poderá também integrar a gestão das diversas políticas sociais estabelecendo redes sociais onde o cliente é considerado na sua totalidade e não apenas em suas demandas setoriais. Essa articulação permitirá que as organizações de um determinado território, sejam estatais, sejam privadas públicas, poderão se integrarem para atender os problemas sociais que afetam a população que ocupa esse território.

Portanto, o processo instaurado pelo Estado com a descentralização, transferindo suas competências para outras instâncias governamentais cria novas possibilidades de gestão e de parcerias. Nesse contexto que as organizações sem fins lucrativos passam a integrar esse movimento e a articular-se em rede com outros organismos estatais e privados, privilegiando a ação intersetorial, que ocasiona a criação de respostas novas aos problemas sociais, em especial na saúde. 
Encontro Pesquisadores Saúde - PUC-SP 28/04/2003

\section{REFERÊNCIAS BILBIOGRÁFICAS}

CASTELLS, Manuel. A Sociedade em Rede, São Paulo; Paz e Terra, 1999

BRESSER PEREIRA, Luiz Carlos. A Reforma do Estado para a Cidadania: a reforma gerencial brasileira na perspectiva internacional, São Paulo: Ed. 34; Brasília: ENAP, 1998

DOWBOR, Ladislau. A Reprodução Social - Propostas para uma Gestão Descentralizada, Petrópolis: Ed. Vozes, 1998

DRAIBE, Sonia. As Políticas Sociais e o neoliberalismo: reflexões suscitadas pelas experiências latino-americanas, Revista USP, 1993, p. 86-101

DRUCKER, Peter. Administração de Organizações Sem Fins Lucrativos princípios e práticas, $2^{\underline{a}}$ ed., São Paulo: Pioneira Editora, 1994

DRUCKER, Peter. As Novas Realidades: no governo e na política, na economia e nas empresas, na sociedade e na visão do mundo, $4^{\underline{a}}$ ed., São Paulo: Pioneira, 1997

FERNANDES, Rubem César. O que é o Terceiro Setor? IOSCHPE, Evelyn B. $3^{\circ}$ SETOR: DESENVOLVIMENTO SOCIAL SUSTENTADO, São Paulo, GIFE/PAZ e TERRA, 1997

GIDDENS, Anthony. As Consequências da Modernidade, São Paulo: Ed. UNESP, 1999

JUNQUEIRA, Luciano A Prates. Descentralização, intersetorialidade e rede como estratégias de gestão da cidade, Revista FEA-PUC SP, São Paulo, vol 1, pp. 5772, nov. 1999

MORIN, Edgar. Complexidade e Ética da Solidariedade, In: CASTRO, G. et al. (org.) Ensaios de Comlexidade, Natal-RN: Editora da UFRN, 1997, 15-24 p OLIVEIRA, Chico de. Políticas Sociais: das carências ao direito do cidadão, São Paulo:FUNDAP. Boletim de Conjuntura-Política Social, No. 14, set/out. 1994:44-46 PAKMAN, Marcelo. Rdes: una metáfora para práctica de intervención social. , In: DABAS, E \& NAJMANOVICH, D.(org.) REDES EL LENGUAJE DE LOS 
VÍNCULOS: Hacia la reconstrucción y el fortalecimiento de la sociedad civil, Buenos Aires: Paidós, 1995, p. 302- 410

RIBEIRO, Sheila M. Reis. Perspectivas da Dinâmica Institucional: A emergência do Setor Público Não-Estatal. (mimeo) II Congresso Interamericano del CLAD sobre Reforma del Estado y de la Administración Pública, Isla de Margarita, Venezuela, 15-18/10/1997, p.2-29

TENÓRIO, Fernando G. Um espectro ronda o Terceiro Setor: o espectro do mercado, Revista de Administração Pública, Rio de Janeiro33(5):85-102, set./out. 1999

THOMPSON, Andrés A . Do Compromisso à Eficiência: Os Caminhos do Terceiro Setor na America Latina. IOSCHPE, Evelyn B. 3 SETOR: DESENVOLVIMENTO SOCIAL SUSTENTADO, São Paulo, GIFE/PAZ e TERRA, 1997 